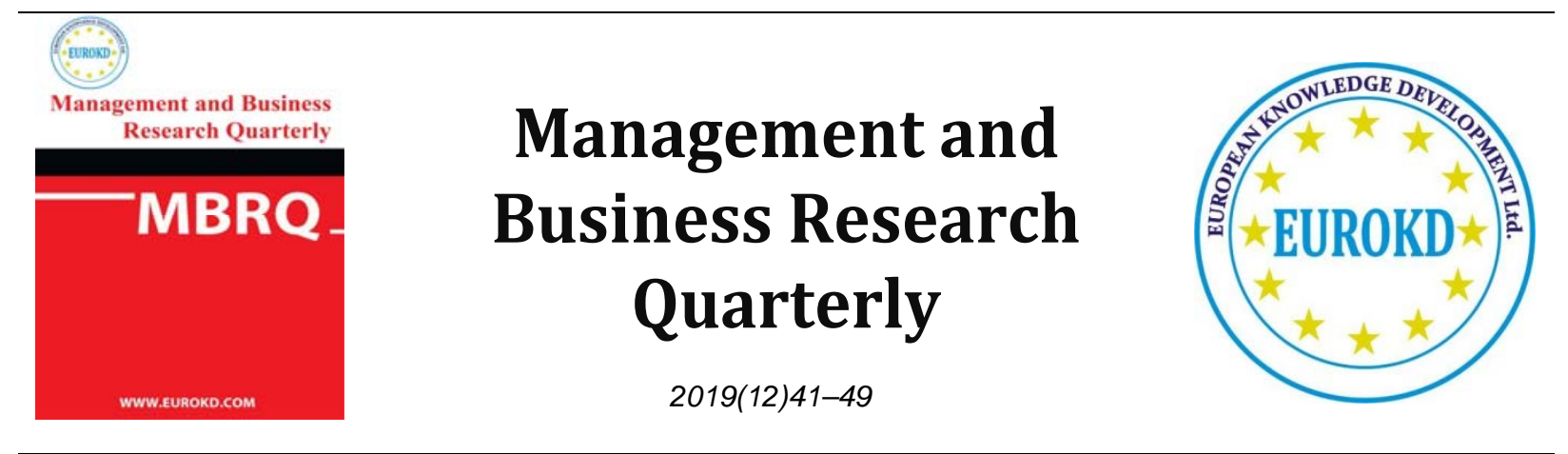

\title{
A study on the Effect of Planned Behavior on Performance by Moderating Role of Individual - organization proportionality among Staff of Ardabil University of Medical Sciences
}

\author{
Behzad Shahbazi*, Majid Ahmadloo
}

Department of Management, Ardabil Branch, Islamic Azad University, Ardabil, Iran

Received 24 October 2019 Accepted 27 December 2019

\begin{abstract}
The purpose of the present study is to study the effect of planned behavior on performance by the moderating role of individual-organization proportionality among staff of Ardabil University of Medical Sciences. The study is an applied one in the purpose, and so descriptive and correlative method, and the research method is field one in data collection. The statistical population of this study includes all staff of Ardabil University of Medical Sciences, 601 employees. Morgan table was used to determine the staff sample size and 234 persons were selected by simple random sampling. For measuring variables, Ahmad Tabatabai et al.'s Planned Behavior Questionnaire (2008), Scruggines' Individualproportionality Inventory (2008), and Hersey \& Gold Smith's Organizational Performance Questionnaire (2008, quoted by Asadi, 2008) were used. Data were analyzed by using SMART PLS software and structural equations were used to analyze the research hypothesis. The findings show that individual-organization proportionality plays a moderating role in the relationship between planned behavior and employee performance. In conclusion, it can be said that relationship between two variables of planned behavior and employee performance is increased by the individualorganization proportionality variable. This can be deduced from the significance and direction of the moderating effect of individual-organization proportionality.

Keywords: Planned Behavior, Performance, Individual-Organization Proportionality
\end{abstract}

\section{Introduction}

Job performance is defined as the expected value of organizations from discrete behavioral events that individuals perform over a specified time period. Job performance is one of the 
most important variables in industrial and organizational psychology and its importance is clear for both individuals and organizations, namely in industrial and organizational psychology, all main activities are focused on improving the job performance (Borman, 2012).

Lexically, performance means as performance state or quality. Therefore, organizational performance is a general structure that refers to how to perform the organizational operations. The most famous definition of performance is presented by Neely, Kennerley, \& Adams (2002): "The process of explaining the quality of effectiveness and efficiency of past actions". According to this definition, performance is divided into two components: 1) the performance that describes how an organization uses resources to produce services or products, ie relationship between actual and desired composition of inputs to produce the certain outputs; and 2) the effectiveness that describes the degree to which organizational goals are attained (Shiri \& Hamedi, 1977).

The importance of performance has led researchers to investigate about it more and more. Performance is defined as total expected values of the organization from discrete behavioral pieces that each individual performs over specified time periods (Shokrkon et al., 2010).

One of the variables that influence on employees' job performance is their planned behavior in the organization. Planned Behavior Theory is used to identify and understand the environmental and individual factors affecting behavior. Theory of Planned Behavior is one of the behavioral change theories that is used to predict and understand behavior and has structures and variables that include the range of behavioral motivation, intention, and display of behavior and its validity has been empirically confirmed in many studies. According to this theory, one of the most important determinants of one's behavior is one's intention, which is influenced by three components of attitude, subjective norms and perceived behavioral control (Ahmadi Tabatabai et al., 2008).

In investigating the effect of planned behavior on performance, we should not neglect the moderating variables. One of the variables that can study the effect of planned behavior on performance is individual-organization proportionality. The word individual-organization proportionality describes the relationship between individual and organizational goals, individual needs and preferences, organizational systems and structures, and individual personality and organizational situation. The underlying assumption is that when to match individual's characteristics and work environment, or at least by having a high degree of congruence, the effectiveness increases, for example, when match between individual characteristics (such as values) and organizational characteristics (such as the cultural values of the organization), or if there is a congruence between individual competencies and job requirements, individuals and organizations will be more effective (Eshaghian et al., 2016).

Individual-organization proportionality is related to the matching of individual and organizational characteristics and it occurs when at least one of them meets other needs or has the same basic characteristics in common; or both. Individual-organization proportionality is a component of the broader concept of individual-environment proportionality that is historically rooted in Lewine's thinking that individual behavior is a function of individual and his environment. Satisfaction, productivity, progress, and stability increase when this proportion is present (Gholipour, 2014).

Therefore, it can be said that staff performance can be influenced by the factors that contribute in its growth and development in Ardabil University of Medical Sciences. However, 
by considering planned behavior and, of course, the moderating role of individual-organization proportionality in this process can help to improve performance while at the same time, lead to increase efficiency at the University of Medical Sciences.

Given the main motivation of the study, it can be said that paying attention to the variable of staff performance in Ardabil University of Medical Sciences is very important and in previous researches the moderating role of individual-organization proportionality in its effect on staff performance was investigated. So, the main question of the present study is how the planned behavior with the moderating role of individual-organization proportionality effects on the staff performance of Ardabil University of Medical Sciences?

\section{Research Methodology}

The research is an applied in purpose, and it is descriptive and correlative in method and in data collecting, the research method is field. For data analysis, PLS SMAR software was used.

\section{Statistical population, sample size and sampling method}

The statistical population of the study includes all the staff of Ardabil University of Medical Sciences with 601 employees. Morgan table was used to determine the sample size and in the case 234 persons were selected by simple random sampling.

\section{Data collection method and tool}

The required information was collected by field referral to the staff of Ardabil University of Medical Sciences. Questionnaire was used to measure the variables.

\section{Planned Behavior}

Planned behavior has 4 dimensions including attitude, behavioral intention, abstract norms and perceived control as measured by Ahmadi Tabatabai et al.'s questionnaire of planned behavior (2008).

Table 1. Dimensions of planned behavior

\begin{tabular}{|c|c|c|}
\hline Items & Dimensions & Concept \\
\hline $\begin{array}{l}\text { In my opinion, the friendly relationship between management and staff creates an emotional } \\
\text { connection between people in the organization. }\end{array}$ & \multirow{6}{*}{ Attitude } & \multirow{14}{*}{$\begin{array}{l}\text { Planned } \\
\text { behavior }\end{array}$} \\
\hline $\begin{array}{l}\text { In my opinion, the friendly relationship between management and staff avoids apathy towards } \\
\text { the organization. }\end{array}$ & & \\
\hline $\begin{array}{l}\text { In my opinion, the interaction between the staff and the client is a sign of the organization's } \\
\text { respect and respect. }\end{array}$ & & \\
\hline In my opinion, this organization supplies its employees better than other organizations. & & \\
\hline If I had to start from the begining, I would still work for this organization. & & \\
\hline There is no partiality in this organization. & & \\
\hline There is no way forward in this organization, as we want it & \multirow{6}{*}{$\begin{array}{l}\text { Behavioral } \\
\text { intention }\end{array}$} & \\
\hline I trust the doctor of the organization as much as my family doctor. & & \\
\hline When it says it wants to take staff into account, it really says the truth. & & \\
\hline The pay system of the organization is such that it encourages conscientious staff. & & \\
\hline Overall, the organization treats us the way we work for it. & & \\
\hline $\begin{array}{l}\text { If I come across an article or interesting article in a newspaper or book, I need to read it all by } \\
\text { word to understand its message. }\end{array}$ & & \\
\hline It is important to me that what I do is related to other things and other people. & & \\
\hline I don't care how the clock works showing the time and the time. & & \\
\hline
\end{tabular}




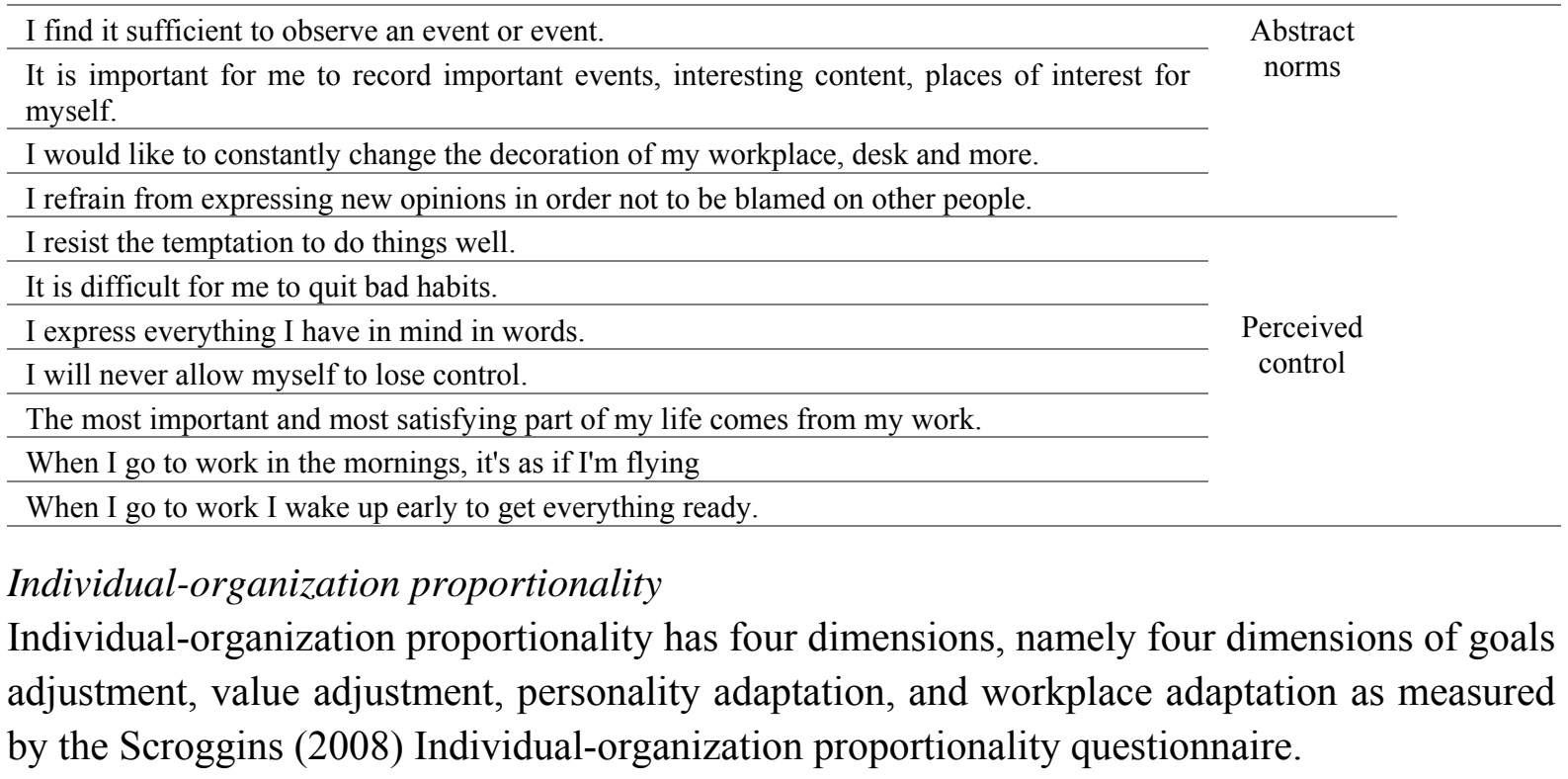

Table 2: Dimensions of individual-organization proportionality

\begin{tabular}{|c|c|c|}
\hline Items & Dimensions & Concept \\
\hline This job requires highly skilled and sophisticated staff. & \multirow{3}{*}{$\begin{array}{c}\text { Goals } \\
\text { adjustment }\end{array}$} & \multirow{15}{*}{$\begin{array}{c}\text { Individual- } \\
\text { organization } \\
\text { proportionality }\end{array}$} \\
\hline The job is almost simple and repetitive. & & \\
\hline $\begin{array}{l}\text { The job requires an employee who does a variety of jobs and has a diverse skill set and } \\
\text { high talent. }\end{array}$ & & \\
\hline $\begin{array}{l}\text { The work is structured, and the employee has no opportunity to comment from the } \\
\text { beginning to the end. }\end{array}$ & \multirow{4}{*}{$\begin{array}{l}\text { Values } \\
\text { adjustment }\end{array}$} & \\
\hline $\begin{array}{l}\text { This job allows the employee to start any part of the job, to be able to complete it } \\
\text { completely. }\end{array}$ & & \\
\hline $\begin{array}{l}\text { The job is just a small part of the whole job done by other people with automated } \\
\text { machines. }\end{array}$ & & \\
\hline Many other people can influence this job by doing well. & & \\
\hline The job is not very important or not important in the whole organization. & \multirow{4}{*}{$\begin{array}{l}\text { Personality } \\
\text { adaptation }\end{array}$} & \\
\hline Job results have important effects on other people's lives and well-being. & & \\
\hline $\begin{array}{l}\text { This job doesn't gives the employee any chance to use his creativity or personal judgment } \\
\text { in doing the job. }\end{array}$ & & \\
\hline $\begin{array}{l}\text { The job gives the employee considerable autonomy and freedom in choosing the way to } \\
\text { do the job. }\end{array}$ & & \\
\hline The job allows the employee to decide for themselves what they need to do. & \multirow{4}{*}{$\begin{array}{l}\text { Workplace } \\
\text { adaptation }\end{array}$} & \\
\hline $\begin{array}{l}\text { The job itself provides valuable guidance to the employee on how to do the job well and } \\
\text { does not require feedback from colleagues or supervisors. }\end{array}$ & & \\
\hline $\begin{array}{l}\text { A detailed job description provides an opportunity for the person to understand how to } \\
\text { do the job well. }\end{array}$ & & \\
\hline The job itself provides very few tips for the person to do well. & & \\
\hline
\end{tabular}

\section{Performance}

Performance has 7 dimensions, namely ability, clarity, assistance, incentive, evaluation, validity and environment as measured by the Hersey \& Gold Smith's organizational performance questionnaire (2008, quoted by Asadi, 1388).

Table 3- Performance Dimensions

\begin{tabular}{|c|c|c|}
\hline Items & Dimensions & Concept \\
\hline To what extent, your field of study is relevant with your job? & & Performance \\
\hline
\end{tabular}


To what extent, your current occupation is associated with your work experience?

Ability

To what extent, your talents and abilities match with your current job?

To what extent, you are responsible for doing things?

To what extent, your job is matter for the organization?

To what extent do you know the purpose of your work?

To what extent are you aware of the priority of your work in the organization?

To what extent are you familiar with the optimal ways to do it?

How much work is done at your workplace based on administrative hierarchy?

Clarity

To what extent do you do the design and planning work for you?

To what extent does the organization try to get people to know their jobs?

To what extent are employees supported by their direct supervisor in performing complex and varied tasks?

To what extent do other departments and subsidiaries have the support and cooperation needed to perform your assigned tasks?

How much cooperation do you have with other parts of the organization?

To what extent do you support your managers when facing personal problems?

To what extent are you persuaded about how to get things done?

How much are you willing and motivated to perform the tasks assigned?

How much do you contribute to the organization's decisions?

To what extent do you benefit from spiritual and material rewards when showing initiative in doing things?

To what extent your current job fits with your interests and desires?

Incentive

How satisfying is your job in terms of content and variety?

To what extent your initiatives and innovations are appreciated?

To what extent is the task you perform as a result of the outstanding performance of an organizational unit?

How much do you know about the quality of the work you do?

To what extent are you aware of ways to improve your performance?

To what extent do you report positive and negative results in a timely manner?

How much do you know about your performance weaknesses?

How much do you know about your performance strengths?

To what extent is the information flow between employees in the in-service training twoway?

How regularly are your works evaluated?

How much do you know about your responsible work expectations for yourself?

To what extent do you value your rights and benefits fairly with what you do for the organization?

How fair are your salary in terms of the type of work and responsibilities in the organization compared to similar employees?

How confident are you in the decisions of your officials?

To what extent is applicable the decisions you make in your field of work?

Validity

To what extent do senior officials' decisions regarding the organization's human resources, such as payroll, employee evaluation, training, promotion, dismissal, etc., comply with employment laws and regulations?

To what extent are the provisions of the law applicable to the decision-making process?

How much do you need to coordinate with other people and units to perform assigned tasks?

To what extent do you have enough budget and credit to do the job?

To what extent are the physical conditions of the workplace respected?

To what extent have you been provided with sufficient equipment and facilities to handle the tasks?

To what extent does the lack of facilities prevent them from doing their jobs?

Reference: Asadi (2009) 
Table 4- Cronbach's alpha coefficient

\begin{tabular}{cccc}
\hline Cronbach's alpha coefficient & Standard deviation & Average & Variable \\
\hline 0.87 & 0.56 & 3.64 & Planned Behavior \\
\hline 0.91 & 0.56 & 3.49 & Individual-organization proportionality \\
0.79 & 0.61 & 3.86 & Organizational performance \\
\hline
\end{tabular}

\section{Findings}

According to model 1 the standardized regression coefficient, effect of the planned behavior on staff performance is $t=2.739$, equal to 0.675 , and standardized regression coefficient of the moderating variable of individual-organization proportionality in relation between planned behavior and Employee performance is $\mathrm{t}=2.167$ which equals 0.552 .

Therefore, the null hypothesis is rejected with $99 \%$ confidence and considering the significance and positive coefficient of this coefficient, it can be stated that individualorganization proportionality plays a moderating role in the relationship between planned behavior and employee performance. This finding shows that the relationship between two variables of planned behavior and employee performance is increased by the individualorganization proportionality variable. This can be deduced from the significance and direction of the moderating effect of individual-organization proportionality. Therefore, the research hypothesis is accepted.

Table 1 - Results of the three Cronbach's alpha measures, convergent reliability and validity

\begin{tabular}{cccc}
\hline Result & Allowed Amount & Value & Model fitting criteria \\
\hline Proper fitting & Alpha $>0 / 7$ & 0.875 & Cronbach's alpha \\
\hline Proper fitting & Alpha $>0 / 7$ & 0.789 & Combined reliability \\
\hline Proper fitting & Alpha $>0 / 5$ & 0.566 & Average variance extracted (AVE) \\
\hline
\end{tabular}

In the main hypothesis, two variables of planned behavior and individual-organization proportionality were able to explain $0.715 \%$ of the variance in employee performance. The remaining percentage is related to the prediction error and may include other factors that are not considered in this study.

In fact, this model tests all measurement equations (factor loadings) and structural equations (path coefficient) using the t-test. According to this model, if the t-test statistic for the paths is greater than 1.96, the path coefficient and the factor load at $95 \%$ confidence level it is significant and if the t-test statistic for paths is less than 1.96, then the factor load or path coefficient is not significant. Also, if the t-test statistic exceeds 2.58, then the coefficient of path and factor loads at $99 \%$ confidence level are significant. 


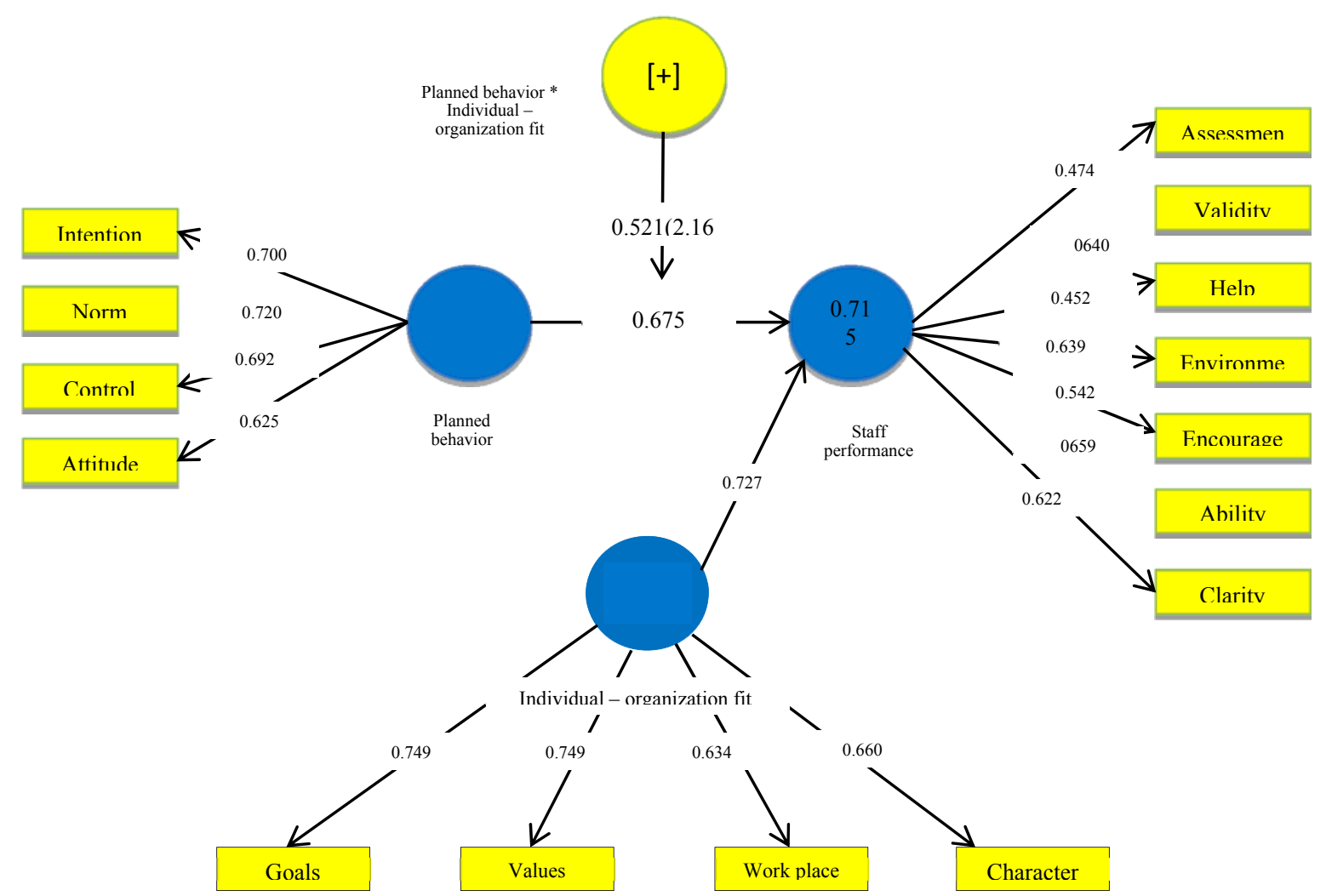

Diagram- 1: Confirmatory factor analysis, measurement and structural model with significant coefficient values t-value, research hypothesis

\section{Conclusions and Suggestions}

In the main hypothesis, independent variable is the planned behavior, a dependent variable is employee performance and moderating variable is individual-organization proportionality. According to the results of the research, the standardized regression coefficient of adjustment of individual-organization proportionality in relation between planned behavior and employee performance is 0.52 .

Therefore, it can be said that the main hypothesis of the research is confirmed and considering the significance and to be positive the coefficient, it can be stated that individualorganization proportionality plays a moderating role in the relationship between planned behavior and employee performance.

Individual-organization proportionality is concerned with the matching of individual and organizational characteristics and occurs when at least one of them meets other needs or has the same basic characteristics in common; or both exist.

Thus, in explaining the main hypothesis of the research, it can be said that the relationship between two variables of planned behavior and employee performance is increased by the individual-organization proportionality variable.

Due to the innovation aspect of the research and since no research is exactly similar to the present one, it is not possible to compare it fully with the findings of previous research, however some findings have some similarities with the present research, which point to a few. 
The results are similar to the findings of Pazd and Rezai (2017). The results show that there is a positive and significant relationship between staff perception of individualorganization proportionality and job performance.

The results are similar to the findings of Rezaian et al. (2017). The results show that public service motivation has an effect on employees' job attitude, but the effect of public service motivation through employee-organization proportionality on employee's job attitude has not been confirmed.

The results are similar to those of Adibpour et al. (2016). The results show that individual-job proportionality and individual-organization fit affect on innovative work behavior and innovative work behavior on employees' job performance. The findings also confirmed the mediating role of trust in creating innovation in the relationship between individual-organization proportionality, individual-job proportionality, and innovative work behavior.

The results show that the relationship between motivation to serve people is positive and significant with both individual-organization and individual-job proportionality. Also, relationship of individual-organization proportionality and individual-job proportionality with job performance is positive and significant. But according to the assumption in the presence of individual-organization proportionality and individual-job proportionality, motivation to serve people was not significantly correlated with performance, confirming the mediating role of these two variables.

Given to the moderating role of individual and organization proportionality, it is recommended that managers, in addition to ongoing staff monitoring and evaluation, establish friendly and emotional relationships with staff so that they can resolve organizational problems and staff performance when necessary and so Improve the university Performance with the necessary planning.

Regarding the effect of planned behavior on performance with moderator role of individual and organization proportionality, university managers are suggested to provide employees with proper and scientific planning to enable employees to achieve the highest level of growth in the organization which can be useful in improving university performance.

Given the moderating role of individual and organization proportionality on the effect of planned behavior on performance, it is suggested that managers make all appointments and divisions based on staff expertise and competence so that staff have the motivation and enthusiasm to contribute to improving university performance.

\section{References}

Adibpour, M.R., Daneshvar, D., \& Dehghan, H. (2016). Effect of Individual Environmental proportionality on Innovative Work Behaviors and Job Performance by Trust Mediation in Creating Innovation, Journal of Management, Economics and Accounting, 4 (3), 105-118.

Ahmadi Tabatabaei, S.V., Taghdisi, M.H., Nakhaei, N., \& Balali Meibodi, F. (2008). The Effect of Educational Intervention Based on Planned Behavior Theory on Physical Activity of Kerman Health Center Staff, Journal of Babol University of Medical Sciences, 12(2),62-69.

Asadi, H. (2009). The Relationship between Learning and Organizational Performance in Physical Education Organization Experts of the Islamic Republic of Iran, Journal of Sport Management, 2(1): 23-40. 
Borman, W. C. (2012). The concept of organizational citizenship. Current Directions in Psycho-logical Science, $13(6), 238-241$.

Gholipour, A. (2014). Explaining individual-organization proportionality as an effective factor in alienation from work and work relationship, Strategic Management Thought, 4(1) ,123-186.

Eshaghian, Z., Kazemi, A., \& Shaemi, A. (2016). Analysis of effect of the individual-organization proportionality and individual-job proportionality on psychological empowerment, Journal of Public Management Research, $9(33), 167-189$.

Neely, A., Kennerley, M., \& Adams, C. (2007). Performance measurement frameworks: a review. Business Performance Measurement, 143-162.

Pazd, M., \& Rezaei, B. (2017). Investigating the Relationship between Individual-Organization proportionality and Job Performance with Emphasis on the Mediating Role of Innovative Working Behavior Case Study: Kermanshah University of Technology First National Conference on Women, Urban Regeneration and Sustainable Development, Tehran.

Rezaeian, A., Taheri, S., \& Gravand, B. (2017). The Impact of Public Sector Employee Motivation on their Job Attitudes with the Moderating Role of Individual-Organization proportionality, Public Management Vision Journal, 7(31),63-78.

Scroggins, W. A. (2008). The relationship between employee fit perceptions, job performance, and retention: Implications of perceived fit. Employee Responsibilities and Rights Journal, 20(1), 57-71.

Shiri, A., \& Hamedi, O. (2018). Investigating the Relationship between Transformational Leadership and Job Performance of Public Administration Staff in Lorestan City, Practical Studies in Management and Development Sciences Third Year, 3 (11), 37-50.

Shokrkon, H., Nisi, A. K., Naami, A., \& Mehrabi Zadeh Artist, M. (2010). Investigating the Relationship between Job Satisfaction with Civil Behavior and Job Performance in Employees of Some Ahwaz Factories, Journal of Shahid Chamran University of Educational Sciences and Psychology (Psychology Special), 3(4), 13-24. 